\title{
Common polymorphic inversions at 17q21.31 and 8p23.1 associate with cancer prognosis
}

\author{
Carlos Ruiz-Arenas ${ }^{1,2,3}$, Alejandro Cáceres ${ }^{1,2,3}$, Victor Moreno ${ }^{4}$ and Juan R. González ${ }^{1,2,3^{*}}$ [D
}

\begin{abstract}
Background: Chromosomal inversions are structural genetic variants where a chromosome segment changes its orientation. While sporadic de novo inversions are known genetic risk factors for cancer susceptibility, it is unknown if common polymorphic inversions are also associated with the prognosis of common tumors, as they have been linked to other complex diseases. We studied the association of two well-characterized human inversions at 17q21.31 and 8p23.1 with the prognosis of lung, liver, breast, colorectal, and stomach cancers.

Results: Using data from The Cancer Genome Atlas (TCGA), we observed that inv8p23.1 was associated with overall survival in breast cancer and that inv17q21.31 was associated with overall survival in stomach cancer. In the metaanalysis of two independent studies, inv17q21.31 heterozygosity was significantly associated with colorectal diseasefree survival. We found that the association was mediated by the de-methylation of cg08283464 and cg03999934, also linked to lower disease-free survival.
\end{abstract}

Conclusions: Our results suggest that chromosomal inversions are important genetic factors of tumor prognosis, likely affecting changes in methylation patterns.

Keywords: Chromosomal inversions, Cancer prognosis, DNA methylation, Genetic epidemiology, Gene expression

\section{Introduction}

Chromosomal inversions are structural genetic variants where a chromosome segment changes its orientation with respect to a reference genome. Chromosomal inversions are either sporadic or polymorphic. Sporadic inversions are infrequent new mutations that have been linked to cancer susceptibility [1-3] and progression [4]. For instance, a sporadic inversion in chromosome 16 is a known precursor of leukemia (reviewed in [5]). By contrast, polymorphic inversions are common variants in the population. Ancient non-recurrent inversions define divergent haplotypes, each linked to an inversion status, as inverted and standard chromosomes do not recombine [6]. Based on this observation, different methods on nucleotide variation data have been implemented to call inversions status from haplotype differences $[7,8]$. Thus, the re-analysis of

\footnotetext{
* Correspondence: juanr.gonzalez@isglobal.org

${ }^{1}$ Barcelona Institute for Global Health, ISGlobal, Doctor Aiguader 88, 08003 Barcelona, Spain

${ }^{2}$ Universitat Pompeu Fabra (UPF), Barcelona, Spain

Full list of author information is available at the end of the article
}

existing GWAS data and bioinformatics tools have allowed the study of the role of polymorphic inversions in complex diseases, such as asthma and obesity [9], neuroticism [10], and ovarian cancer [11]. Since no study has reported associations with cancer prognosis, we asked the extent to which polymorphic inversions are also related to the prognosis of common cancers that included lung, liver, stomach, breast, and colorectal.

We studied the role of the inversions at $8 \mathrm{p} 23.1$ and $17 \mathrm{q} 21.31$ in cancer prognosis as these two inversions are well-characterized and can be genotyped to high accuracy using SNP array data $[6,8,12]$. Gene expression and methylation data analyses were performed to assess the transcriptomic and epigenomic effects of inversions and their potential effects on prognosis. Mediation analyses were carried out to determine whether gene expression or DNA methylation are suitable mediators of the association between inversions and cancer prognosis.

(C) The Author(s). 2019 Open Access This article is distributed under the terms of the Creative Commons Attribution 4.0 International License (http://creativecommons.org/licenses/by/4.0/), which permits unrestricted use, distribution, and reproduction in any medium, provided you give appropriate credit to the original author(s) and the source, provide a link to the Creative Commons license, and indicate if changes were made. The Creative Commons Public Domain Dedication waiver (http://creativecommons.org/publicdomain/zero/1.0/) applies to the data made available in this article, unless otherwise stated. 


\section{Materials and methods} Inversion calling on TCGA

We obtained TCGA SNP data in Birdseed format from NCI Genomic Data Commons (GDC) legacy archive [13]. We converted the data to VCF format and mapped them to the human assembly hg19 using birdseed2vcf [14]. We imputed the SNPs with the Michigan server [15], using HRC Version r1.1 2016 as the reference and SHAPEIT v2.r790 as the phasing algorithm. We used peddy [16] to select individuals detected as European with a confidence higher than 0.9. Inversion genotypes for inv8p23.1 and inv17q21.31 were obtained using scoreInvHap that uses SNP information on inversion regions to call inversion genotypes $[8,17]$.

\section{CRCGEN}

The CRCGEN study combines data of three case-control studies performed in Spain. The first study was performed in the University Hospital of Bellvitge, L'Hospitalet, Barcelona, and recruited 304 incidents, pathology confirmed, colorectal cancer (CRC) cases and 293 age and sex frequency-matched hospital controls during the period 1996-1998. The second study, performed in the same hospital during the period 2007-2015, included a total of 324 cases and 376 population controls. The third study was conducted in Hospital of León, León, during 2008-2013. A total of 325 incident CRC cases and 407 population controls were included. Written informed consent was required from all participants. Each Hospital's ethics committees (Bellvitge and León) approved the protocols of the study. The three studies contributed to CORECT consortium, so genotyping and quality control was performed simultaneously for all subjects.

\section{Survival analysis}

We selected the cancers with the highest worldwide mortality [18]: lung, liver, colorectal, stomach, and breast. In TCGA, these cancers corresponded to LUAD (lung adenocarcinoma), LUSC (lung squamous cell carcinoma), LIHC (liver hepatocellular carcinoma), COAD (colon adenocarcinoma), READ (rectum adenocarcinoma), STAD (stomach adenocarcinoma), and BRCA (breast invasive carcinoma). We considered LUAD and LUSC as two independent cancers and COAD and READ as one single cancer (i.e., colorectal). We only considered female samples for breast cancer associations. We downloaded TCGA clinical data using curatedTCGAData [19]. We fitted survival and disease-free-survival (i.e., recurrence) Cox proportional hazards models. Inversion genotypes for inv17q21.31 and inv8p23.1 were considered as risk factors under four different genetic models: (1) additive (Std-Std, 0; Std-Inv, 1; Inv-Inv, 2); (2) dominant (Std-Std, 0; Std-Inv, 1; Inv-Inv, 1); (3) recessive (Std-Std, 0; Std-Inv, 0; Inv-Inv, 1), and (4) overdominant
(Std-Std, 0; Std-Inv, 1, Inv-Inv; 0). We accounted for multiple testing using Bonferroni correcting for four genetic models, considering significant $p$ values that were lower than $1.19 \times 10^{-3}$. For all tumors, we tested a univariate and a multivariate model adjusted for age, gender, pathologic stage (stage I, stage II, stage III, and stage IV), and the first four genome-wide principal components inferred by peddy [16].

Using the CRCGEN study, we tested the replication of the significant associations found for colorectal cancer. We genotyped inversions using scoreInvHap on 760 patients with complete information on the selected covariates. We fitted a frailty Cox proportional hazard model for the significant associations previously found, adjusting for age, gender, pathologic stage, cancer site, and recruitment city as random effect to control for possible confounding related to recruiting process. The asymptotic power based on an approximate variance formula implemented in the survSNP $R$ package [20] was used to estimate the power of replicating the increased risk of colorectal recurrence and inversion 17q21.31 assuming an additive model (overdominant is not implemented in the package). We meta-analyzed the results of TCGA and CRCGEN models using metafor $\mathrm{R}$ package [21].

\section{Gene expression analysis}

We downloaded the GDC harmonized version of gene expression data using TCGAbiolinks [22]. We merged COAD and READ datasets and we selected samples from primary tumor, with reported pathologic stage and with inversion status inferred by scoreInvHap. We removed genes with less than ten counts in more than $1 \%$ of the samples and we transformed count values to $\log _{2}$ CPMs using voom [23]. The final dataset contained 477 individuals and 27,291 genes, where we tested the association between gene expression and inv17q21.31 using robust linear models and redundancy analysis (RDA) [24], as implemented in MEAL [25]. Both models included age, gender, pathologic stage, PC genetic components, and 53 surrogate variables as covariates. We accounted for multiple testing in robust linear model analysis using Benjamini-Hochberg method [26]. The results were mapped to gene coordinates in human assembly hg19 using biomaRt [27, 28].

\section{DNA methylation analysis}

We downloaded the GDC harmonized version of DNA methylation data using TCGAbiolinks. We merged COAD and READ datasets and we selected samples from primary tumor. We removed probes with SNPs as defined in the minfi package [29], in sexual chromosomes and likely to cross-hybridize [30]. The final dataset contained 265 individuals and 350,879 CpGs. MEAL 
package [25] was used to associate inv17q21.31 with DNA methylation. We fitted robust linear models to detect differentially methylated probes (DMP); we also used redundancy analysis in the inverted region and three methods to detect differentially methylated regions (DMRs): bumphunter [31], blockFinder [29], and DMRcate [32]. All the models included age, gender, pathologic stage, PC genetic components, and 37 surrogate variables as covariates. We accounted for multiple testing in robust linear model analysis using BenjaminiHochberg adjustment. We reported the genes mapped to CpG using Release 93 of ENSEMBLE nomenclature.

\section{Mediation analysis}

We evaluated whether gene expression or DNA methylation were mediators of the association between inversion inv17q21.31 and colorectal recurrence. We accounted for technical bias on gene expression and DNA methylation by computing residuals, removed from the effect of surrogate variables. We evaluated whether gene expression mediated the effect of inv17q21.31 on tumor recurrence using the genes previously associated with the inversion. Four hundred seventy-seven samples were available with gene expression and clinical data. The mediation test included a generalized linear model (gene vs inversion) and a regression parametric model (tumor recurrence vs inversion + gene), both adjusted for age, sex, pathologic stage, and the first four genome-wide principal components. We run 1000 permutations to compute the significance of the mediation and used the same method for the mediation of the association between inv17q21.31 and disease-free survival. We tested whether the CpGs affected by the inversion associated with tumor recurrence, using a Cox proportion hazards regression model. We selected those CpGs associated with tumor recurrence either in a crude model or after adjusting for age, sex, pathologic stage, and the first four genome-wide principal components ( $p$ value $<0.05)$. We performed mediation tests with the mediation $\mathrm{R}$ package [33].

\section{Results}

Chromosomal inversions associate with overall and disease-free cancer survival

Table 1 shows the patients characteristics included in the study. We did not find an association between chromosomal inversions at 8p23.1 and 17q21.31 and general patients' features.

We tested the association of inv8p23.1 and inv17q21.31 with overall survival using an unadjusted model (Table 2). We observed that the inverted homozygous for inv8p23.1 associated with lower breast cancer survival (HR 2.01, $p$ value $2.7 \times 10^{-3}$ ) but with higher stomach cancer survival (HR $0.42, p$ value $3.3 \times 10^{-2}$ ), whereas standard homozygous for inv17q21.31 associated with low survival of

Table 1 Individual characteristics in TCGA datasets

\begin{tabular}{|c|c|c|c|c|c|c|}
\hline & Lung1 $(n=381)$ & Lung2 $(n=399)$ & Liver $(n=140)$ & Colorectal $(n=470)$ & Stomach $(n=240)$ & Breast $(n=734)$ \\
\hline \multicolumn{7}{|l|}{ Inv8p23.1 } \\
\hline Std-Std & $59(15.5 \%)$ & $81(20.3 \%)$ & $21(15.0 \%)$ & $88(18.7 \%)$ & 55 (22.9\%) & $128(17.5 \%)$ \\
\hline Std-Inv & $205(53.8 \%)$ & 207 (51.9\%) & $83(59.3 \%)$ & 219 (46.6\%) & 115 (47.9\%) & $376(51.2 \%)$ \\
\hline Inv-Inv & $117(30.7 \%)$ & $111(27.8 \%)$ & $36(25.7 \%)$ & $163(34.7 \%)$ & $14(29.2 \%)$ & $230(31.3 \%)$ \\
\hline \multicolumn{7}{|l|}{ Inv17q21.31 } \\
\hline Std-Std & $225(59.1 \%)$ & $244(61.1 \%)$ & $83(59.3 \%)$ & $294(62.7 \%)$ & $158(65.8 \%)$ & $453(61.7 \%)$ \\
\hline Std-Inv & $140(36.7 \%)$ & $128(32.1 \%)$ & $49(35.0 \%)$ & $162(34.5 \%)$ & $68(28.3 \%)$ & $250(34.1 \%)$ \\
\hline Inv-Inv & $16(4.2 \%)$ & $27(6.8 \%)$ & $8(5.7 \%)$ & $14(2.97 \%)$ & $14(5.8 \%)$ & $31(4.2 \%)$ \\
\hline Age (years) & $67(33-88)$ & $69(40-90)$ & $65(17-85)$ & $69(31-90)$ & $67(41-90)$ & $60(26-90)$ \\
\hline \multicolumn{7}{|l|}{ Sex } \\
\hline Women & 205 (53.8\%) & 99 (24.8\%) & $68(48.6 \%)$ & 225 (47.9\%) & 93 (38.8\%) & 734 (100\%) \\
\hline Men & $176(46.2 \%)$ & $300(75.2 \%)$ & $72(51.2 \%)$ & $245(52.1 \%)$ & 147 (61.3\%) & $0(0 \%)$ \\
\hline \multicolumn{7}{|l|}{ Tumor stage } \\
\hline Stage I & $210(55.1 \%)$ & $198(49.6 \%)$ & $67(47.9 \%)$ & $88(18.7 \%)$ & $35(14.6 \%)$ & $129(17.6 \%)$ \\
\hline Stage II & $87(22.8 \%)$ & $129(32.3 \%)$ & $36(25.7 \%)$ & $176(37.4 \%)$ & $68(28.3 \%)$ & 404 (55.0\%) \\
\hline Stage III & $64(16.8 \%)$ & $66(16.6 \%)$ & $34(24.3 \%)$ & 138 (29.4\%) & 112 (46.7\%) & $179(24.4 \%)$ \\
\hline Stage IV & $20(5.3 \%)$ & $6(1.5 \%)$ & $3(2.1 \%)$ & $68(14.5 \%)$ & $25(10.4 \%)$ & $22(3.0 \%)$ \\
\hline Follow-up time (days) & $609(0-7248)$ & $671(0-4765)$ & $662(0-3478)$ & $648(0-4502)$ & $415(0-3720)$ & $838(0-8605)$ \\
\hline
\end{tabular}

Continuous variables are described with median and range. Categorical variables are described with counts and the percentages of each category Lung1 LUAD (lung adenocarcinoma), Lung2 LUSC (lung squamous cell carcinoma), Liver LIHC (liver hepatocellular carcinoma), Colorectal COAD + READ (colon adenocarcinoma), Stomach STAD (Stomach adenocarcinoma), Breast BRCA (breast invasive carcinoma) 
Table 2 Hazard ratios (HR) of overall survival using Cox regression models

\begin{tabular}{|c|c|c|c|c|c|c|c|c|}
\hline \multirow[t]{2}{*}{ Tumor } & \multicolumn{4}{|c|}{ inv8p23.1 } & \multicolumn{4}{|c|}{ inv17q21.31 } \\
\hline & Std-Std & Std-Inv & Inv-Inv & $p$ value & Std-Std & Std-Inv & Inv-Inv & $p$ value \\
\hline Lung1 & \multicolumn{3}{|c|}{$1.10(0.80-1.50)$} & 0.55 & \multicolumn{3}{|c|}{$0.78(0.55-1.12)$} & 0.18 \\
\hline Lung2 & 1 & 1 & $0.96(0.65-1.42)$ & 0.84 & 1 & 1 & $0.72(0.35-1.47)$ & 0.37 \\
\hline Liver & 1 & 1 & $0.84(0.45-1.55)$ & 0.58 & 1 & $0.74(0.42-1.30)$ & 1 & 0.30 \\
\hline Colorectal & 1 & $0.68(0.38-1.19)$ & 1 & 0.18 & 1 & $0.74(0.40-1.36)$ & 1 & 0.33 \\
\hline Stomach & 1 & 1 & $0.42(0.18-0.93)$ & $3.3 \times 10^{-2}$ & 1 & $2.19(1.20-3.99)$ & $2.19(1.20-3.99)$ & $1.1 \times 10^{-}$ \\
\hline Breast & 1 & 1 & $2.00(1.27-3.16)$ & $2.6 \times 10^{-3}$ & \multicolumn{3}{|c|}{$1.34(0.93-1.94)$} & 0.12 \\
\hline
\end{tabular}

The results are shown for the best genetic model for each inversion in each tumor. Associations in italics were nominally significant ( $p$ value $<0.05$ ). In the additive model, HR corresponds to each inverted allele. For the other models, HR was computed using Std-Std as reference Lung1 LUAD (lung adenocarcinoma), Lung2 LUSC (lung squamous cell carcinoma), Liver LIHC (liver hepatocellular carcinoma), Colorectal COAD + READ (colon adenocarcinoma), Stomach STAD (stomach adenocarcinoma), Breast BRCA (breast invasive carcinoma)

stomach cancer $\left(\mathrm{HR} 2.19, p\right.$ value $\left.1.1 \times 10^{-2}\right)$. After adjusting for sex, age, tumor stage, and the first four genetic principal components, we found that the association between inv8p23.1 and breast cancer survival further increased (HR 2.55, $p$ value $1.4 \times 10^{-4}$ ), likewise the association between inv17q21.31 and stomach cancer survival (HR 3.26, $p$ value $5.8 \times 10^{-4}$ ) (Additional file 1 , Supplementary Tables 1-2). However, the adjustment removed the significant association between inv8p23.1 and stomach cancer (HR 0.62, $p$ value 0.14) (Additional file 1, Supplementary Table 2). Note that all reported associations were statistically significant under Bonferroni threshold $\left(1.19 \times 10^{-3}\right)$. Multivariate models confirmed that pathologic stage and age are strong predictors of overall survival (Additional file 1, Supplementary Tables 1-6).

We then tested the association between inv8p23.1 and inv17q21.31 with disease-free survival (Table 3). Only one significant association was significant, between heterozygous individuals for inv17q21.31 and decreased tumor disease-free survival in colorectal cancer (HR 1.67, $p$ value $1.6 \times 10^{-2}$ ) (Fig. 1, Table 3). After adjusting for age, sex, tumor stage, and the first four genetic principal components, the association was on the limit of Bonferroni correction (HR 1.81, $p$ value $7.2 \times 10^{-3}$ ) (Additional file 1 ,
Supplementary Table 7). Such overdominant model is plausible as inversion heterozygous affect chromosome pairing which can lead to genomic alterations [34]. In addition, the multivariate models confirmed that the pathologic stage is a strong predictor of disease-free survival (Additional file 1, Supplementary Tables 7-12).

We then tested the replication of inv17q21.31 association using the colorectal CRCGEN study. We had a 99.5\% power to detect a $\mathrm{HR}=1.81$ for recurrence assuming $\alpha=$ 0.05 , a 0.24 inversion allele frequency, 0.21 recurrent event rate, and an additive model. Participants of this study had different characteristics than TCGA patients (Additional file 1, Supplementary Table 13). We observed, in a fully adjusted model (age, sex, tumor stage, and patients' city), that while heterozygous individuals for inv17q21.31 decreased tumor disease-free survival, the association was not statistically significant (HR 1.16, $p$ value 0.33 ) (Additional file 1 , Supplementary Table 14). However, the association was significant in the meta-analysis of TCGA and CRCGEN studies (HR 1.34, $p$ value $2.3 \times 10^{-2}$ ) (Fig. 1). We further asked whether the observed overdominance of inv17q21.31 in colorectal disease-free survival was supported by functional associations with gene expression and DNA methylation in the TCGA study.

Table 3 Crude Cox regression models between chromosomal inversions and disease-free survival

\begin{tabular}{|c|c|c|c|c|c|c|c|c|}
\hline \multirow[t]{2}{*}{ Tumor } & \multicolumn{4}{|c|}{ inv8p23.1 } & \multicolumn{4}{|c|}{ inv17q21.31 } \\
\hline & Std-Std & Std-Inv & Inv-Inv & $p$ value & Std-Std & Std-Inv & Inv-Inv & $p$ value \\
\hline Lung1 & \multicolumn{3}{|c|}{$0.78(0.61-1)$} & 0.05 & \multicolumn{3}{|c|}{$0.88(0.67-1.16)$} & 0.37 \\
\hline Lung2 & 1 & $0.82(0.52-1.28)$ & $0.82(0.52-1.28)$ & 0.38 & 1 & 1 & $0.49(0.2-1.2)$ & 0.12 \\
\hline Liver & 1 & 1 & $1.01(0.61-1.68)$ & 0.96 & 1 & $1.13(0.74-1.74)$ & $1.13(0.74-1.74)$ & 0.57 \\
\hline Colorectal & 1 & $0.86(0.51-1.44)$ & $0.86(0.51-1.44)$ & 0.56 & 1 & $1.67(1.1-2.53)$ & 1 & $1.57 \times 10^{-2}$ \\
\hline Stomach & 1 & 1 & $0.79(0.44-1.4)$ & 0.42 & 1 & $0.98(0.57-1.68)$ & 1 & 0.93 \\
\hline Breast & 1 & $0.66(0.41-1.04)$ & 1 & 0.08 & 1 & 1 & $2.01(0.81-4.99)$ & 0.13 \\
\hline
\end{tabular}

The results are for the best genetic model for each inversion in each tumor. Associations in italics were nominally significant $(p$ value $<0.05)$. In the additive model, HR corresponds to each inverted allele. For the other models, HR was computed using Std-Std as the reference

Lung1 LUAD (lung adenocarcinoma), Lung2 LUSC (lung squamous cell carcinoma), Liver LIHC (liver hepatocellular carcinoma), Colorectal COAD + READ (colon adenocarcinoma), stomach: STAD (stomach adenocarcinoma), Breast BRCA (breast invasive carcinoma) 


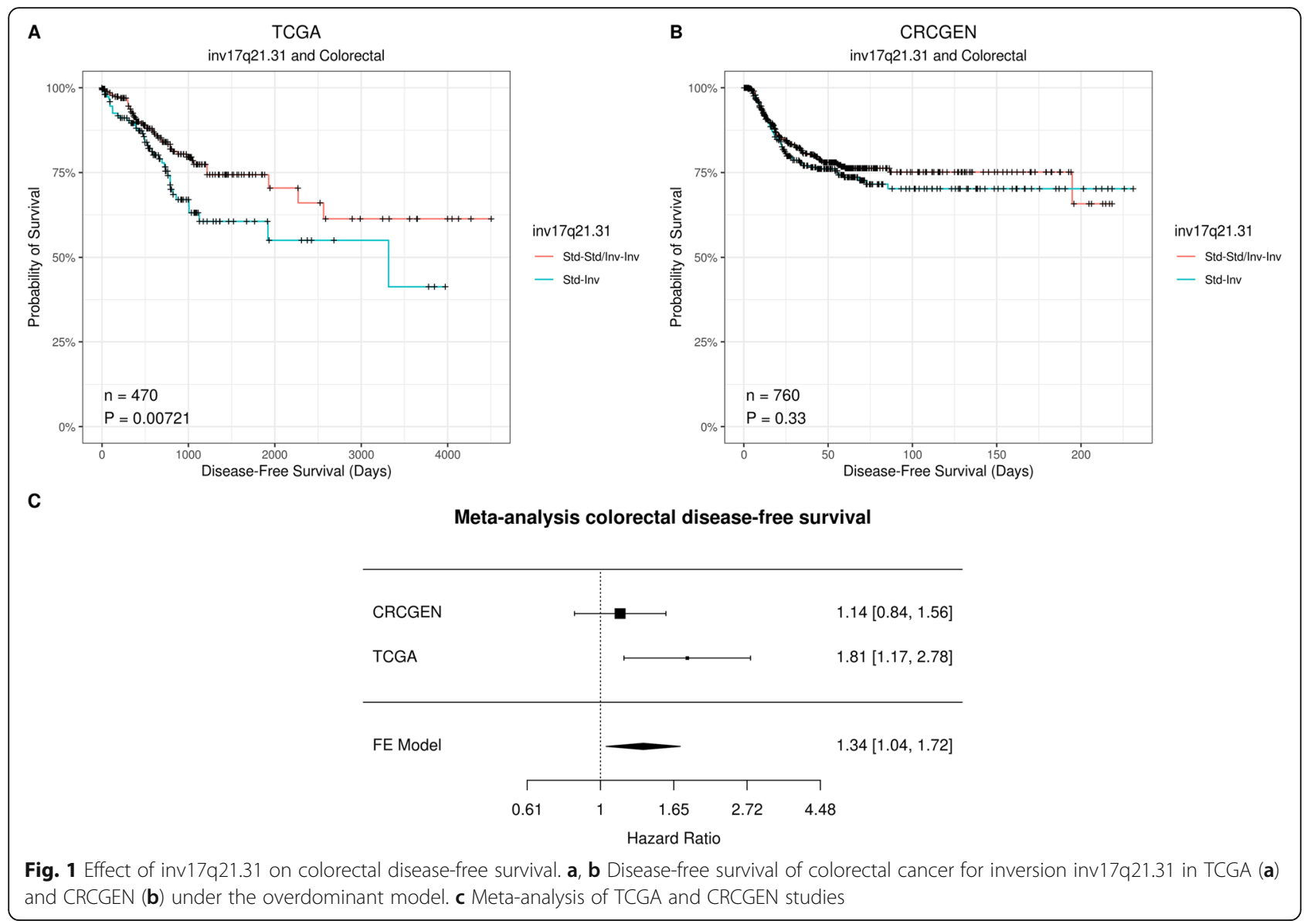

\section{inv17q21.31 effect on colorectal disease-free survival is more likely mediated by DNA methylation than by gene expression}

We aimed to find a molecular mechanism to explain the effect of inv17q21.31 on colorectal disease-free survival using TCGA data. To this end, we tested two different hypotheses: (1) a change in the expression of a gene mediates the association between the inversion and disease-free survival and (2) specific changes in DNA methylation, which may regulate the expression of several genes and mediate the association between the inversion and disease-free survival.

Heterozygous for inv17q21.31 were associated with significant differences in the expression of 12 genes within inv17q21.31 region (Additional file 1, Supplementary Table 15) and explained $10 \%$ of the gene expression variability (Additional file 1, Supplementary Figure 2). At genome-wide level, inversion inv17q21.31 changed the expression of another five genes (Additional file 1, Supplementary Table 15). However, none of the genes affected by the inversion mediated the association between inv17q21.31 and colorectal disease-free survival.

Heterozygous for inv17q21.31 were associated with significant changes in methylation of $11 \mathrm{CpGs}$ inside the inversion region (Additional file 1, Supplementary Table 16). However, the CpGs only explained $1 \%$ of methylation variability (Additional file 1, Supplementary Figure 3). Significant methylated regions (DMRs) in inv17q21.31 were also detected with Bumphunter and DMRcate for inverted heterozygous (Additional file 1, Supplementary Tables 17-18). At genome-wide level, inv17q21.31 changed the methylation of other $87 \mathrm{CpGs}$ in different chromosomes (Additional file 1, Supplementary Table 16). We found that six of these CpGs also associated with disease-free survival. We then tested the mediation of these six CpGs in the association between the inversion and disease-free survival and found two CpGs with significant mediation effects: cg08283464 mediated a $15.0 \%$ of the association ( $p$ value, 0.048 ) and cg03999934 a 20.7\% ( $p$ value, 0.032). In particular, both CpGs had lower methylation in heterozygous individuals (Fig. 2a, Additional file 1, Supplementary Table 16), consistent with the observation that lower methylation values were associated to lower tumor disease-free survival (HR 0.015, $p$ value 0.017 for cg08283464; HR 0.034, $p$ value $9.9 \cdot 10^{-4}$ for cg03999934) (Fig. 2b, Additional file 1, Supplementary Table 19). 


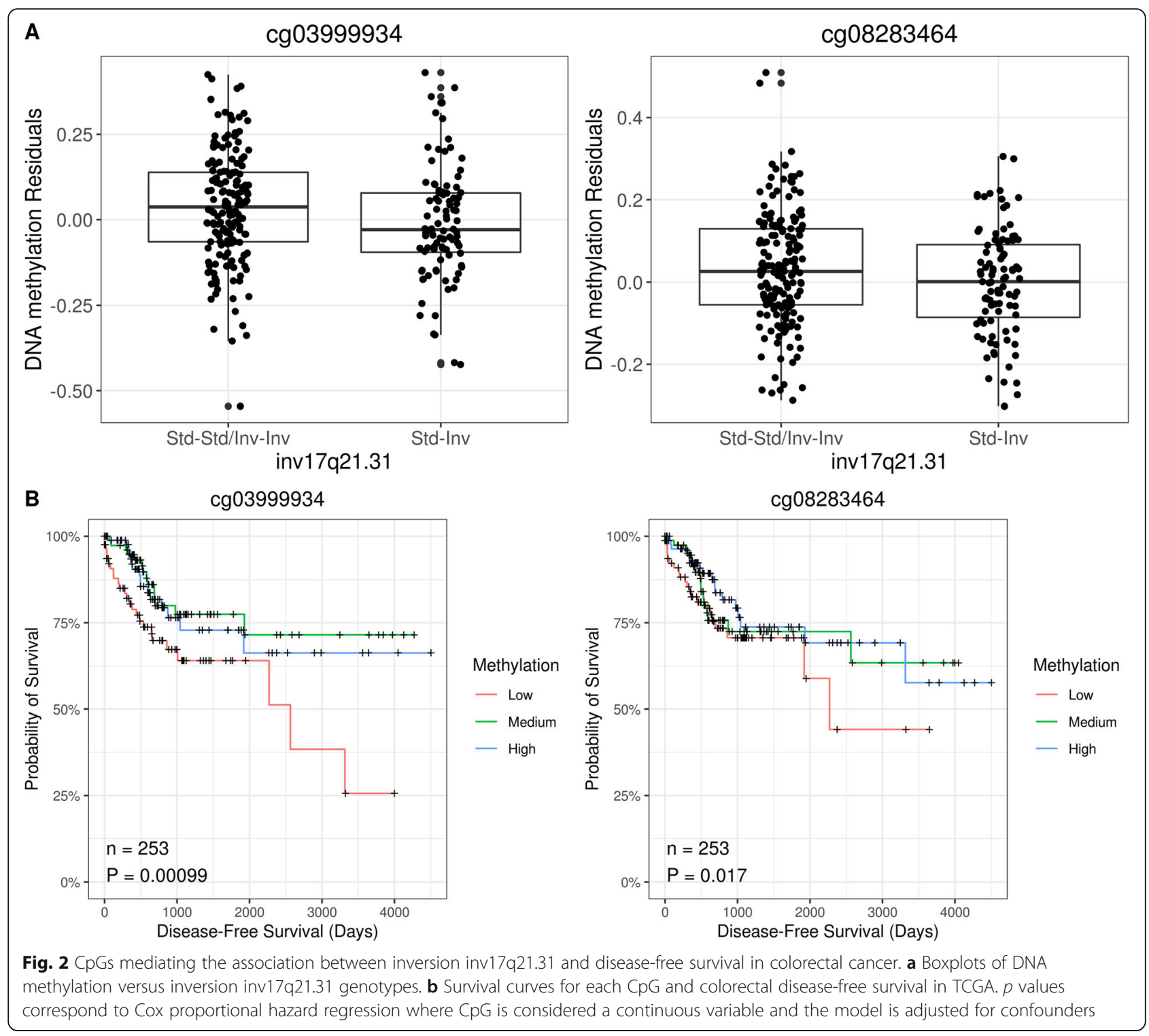

\section{Discussion}

We found that chromosomal inversions at 8p23.1 and 17q21.31 affect tumor prognosis in breast, stomach, and colorectal cancer. These new biomarkers should be further considered in prognosis assessment in addition to the SNPs associated with breast and stomach cancer survival [35-37] and with colorectal cancer recurrence [38, 39 ] and in addition to germline CNVs associated with breast and colorectal cancer prognosis [40-42]. As such, further studies need to evaluate the increased power of polygenic scores of prognosis and susceptibility given by the inclusion of these inversions [43]. The inversions have the potential to improve polygenic scores by including common genomic structural variants and by specifically including variants associated with prognosis [44].
Inversions inv8p23.1 and inv17q21.31 were associated with overall survival based on dominant and recessive genetic models. Both inversions have already been associated with different diseases. inv8p23.1 has been associated with system systematic lupus [45, 46], neuroticism [10], autism [47], schizophrenia [47], and underweight [12], and inv17q21.31 has been associated with Parkinson [4851], neurodegenerative tauopathies [52, 53], Alzheimer's disease [54], neuroticism [10], autism [47], schizophrenia [47], or response to corticosteroids in asthma [55].

Inversion heterozygous at $17 \mathrm{q} 21.31$ predicted lower disease-free survival in colorectal cancer. While overdominance is uncommon for SNPs, inversion heterozygous have shown deleterious effects on complex phenotypes, such as congenital ichthyosis [56], where non-allelic homologous recombination (NAHR) that 
reverts the effect of detrimental mutations is impaired in inverted heterozygous. A similar mechanism could explain the worse colorectal cancer prognosis of inverted heterozygous. Another mechanism for the overdominant effect of the inversion could be linked to the deletion of the region during mitosis, as inverted heterozygous favor the generation of such chromosome rearrangements [34]. Further research is needed to elucidate the specific mechanisms for the lower prognosis of inv17q21.31 heterozygous.

In this work, we tested two possible mediators between inversion inv17q21.31 and disease-free survival: (1) expression changes in specific genes and (2) DNA methylation changes in specific CpGs, which could correlate with the expression of several genes. Our results support DNA methylation changes as the more likely mediators. We did not observe a mediation effect of these genes on the overdominance of inv17q21.31 on disease-free survival, although inv17q21.31 heterozygous were associated with gene expression on colorectal tumors, in line with previous studies in blood and brain [53, 57-60]. However, we cannot discard that the overall mediatory effect is given by the additive contribution of small independent effects of each gene, for which there is lack of statistical power. On the other hand, the association between inv17q21.31 heterozygous with extensive genome-wide changes in DNA methylation on colorectal tumor tissue underlines the genome-wide role of the inversion, already observed for genome-wide gene expression changes in blood [53], and global recombination [61]. We found that the two CpGs that partially mediated the effect of inv17q21.31 on colorectal diseasefree survival are intergenic and have the potential to affect the transcription of several genes. While DNA methylation clearly affects colorectal recurrence $[62,63]$ and changes in DNA methylation have also been observed to mediate the effect of inv17q21.31 on diseases [53], the effect of inv17q21.31 in global epigenetic patterns needs further investigation.

In conclusion, we offer novel evidence on the effect of common inversion polymorphisms on the tumor prognosis of common cancers, indicating underlying epigenomic mechanisms linking inv17q21.31 to colorectal disease-free survival. Although more research is needed to validate the associations between inv17q21.31 heterozygosity and colorectal cancer disease-free survival, we show significant functional correlations that support our observations.

\section{Supplementary information}

Supplementary information accompanies this paper at https://doi.org/10. 1186/s40246-019-0242-2.

Additional file 1. Supplementary Figures and Tables (.pdf)

\section{Acknowledgements}

The results shown here are in whole or part based upon data generated by the TCGA Research Network: http://cancergenome.nih.gov/. TCGA genetic data was obtained from dbGaP: accession number phs000178.v10.p8.

\section{Authors' contributions}

CR-A run the analyses and wrote a first draft of the paper. AC, VM, and JRG helped in writing the last version of the paper. JRG supervised the project. All authors read and approved the final manuscript.

\section{Funding}

This research has received funding from Ministerio de Ciencia, Innovación y Universidades (MICIU), Agencia Estatal de Investigación (AEI) and Fondo Europeo de Desarrollo Regional, UE (RTI2018-100789-B-100). CR-A was supported by a Fl fellowship from Catalan Government (\#016FI_B 00272).

\section{Availability of data and materials}

Data from TCGA is available from Genomic Data Commons: https://gdc. cancer.gov/. TCGA genetic data was obtained from dbGaP: accession number phs000178.v10.p8. Data from CRCGEN will be uploaded to a public repository after manuscript acceptance.

\section{Ethics approval and consent to participate}

In CRCGEN dataset, written informed consent was required from all participants. Each Hospital's ethics committees (Bellvitge and León) approved the protocols of the study.

\section{Consent for publication}

Not applicable

\section{Competing interests}

The authors declare that they have no competing interests.

\section{Author details}

${ }^{1}$ Barcelona Institute for Global Health, ISGlobal, Doctor Aiguader 88, 08003 Barcelona, Spain. ${ }^{2}$ Universitat Pompeu Fabra (UPF), Barcelona, Spain. ${ }^{3} \mathrm{CIBER}$ Epidemiología y Salud Pública (CIBERESP), Barcelona, Spain. ${ }^{4}$ Programa de Prevención y Control del Cáncer, Instituto Catalán de Oncología, L'Hospitalet, Barcelona, Spain.

Received: 1 January 2019 Accepted: 9 October 2019

Published online: 21 November 2019

References

1. Yamazaki H, Suzuki M, Otsuki A, Shimizu R, Bresnick EH, Engel JD, et al. A remote GATA2 hematopoietic enhancer drives leukemogenesis in inv(3)(q21;q26) by activating EVI1 expression. Cancer Cell [Internet]. Elsevier; 2014 [cited 2017 May 4];25. Available from: http://www.ncbi.n/m.nih.gov/ pubmed/24703906

2. Rhees J, Arnold M, Boland CR. Inversion of exons 1-7 of the MSH2 gene is a frequent cause of unexplained Lynch syndrome in one local population. Fam Cancer [Internet]. NIH Public Access; 2014 [cited 2018 Jun 1];13:219-25. Available from: http://www.ncbi.n/m.nih.gov/pubmed/24114314

3. Soda M, Choi YL, Enomoto M, Takada S, Yamashita Y, Ishikawa S, et al. Identification of the transforming EML4-ALK fusion gene in non-small-cell lung cancer. Nature [Internet]. Nature Publishing Group; 2007 [cited 2018 Jun 1];448: 561-566. Available from: http://www.nature.com/articles/nature05945

4. Gruber TA, Larson Gedman A, Zhang J, Koss CS, Marada S, Ta HQ, et al. An Inv(16)(p13.3q24.3)-encoded CBFA2T3-GLIS2 fusion protein defines an aggressive subtype of pediatric acute megakaryoblastic leukemia. Cancer Cell [Internet]. Elsevier; 2012 [cited 2018 Jun 1];22:683-697. Available from: http://linkinghub.elsevier.com/retrieve/pii/S1535610812004382

5. Pulikkan JA, Castilla LH. Preleukemia and leukemia-initiating cell activity in inv(16) acute myeloid leukemia. Front Oncol [Internet]. Frontiers; 2018 [cited 2018 Jun 1];8:129. Available from: https://doi.org/10.3389/fonc.2018.00129/full

6. Salm MPA, Horswell SD, Hutchison CE, Speedy HE, Yang X, Liang L, et al. The origin, global distribution, and functional impact of the human 8p23 inversion polymorphism. Genome Res [Internet]. 2012 [cited 2017 May 4];22: 1144-53. Available from: http://www.ncbi.nlm.nih.gov/pubmed/22399572 
7. Cáceres A, Sindi SS, Raphael BJ, Cáceres M, González JR. Identification of polymorphic inversions from genotypes. BMC Bioinformatics [Internet]. 2012;13:28. Available from: https://doi.org/10.1186/1471-2105-13-28

8. Ruiz-Arenas C, Cáceres A, López-Sánchez M, Tolosana I, Pérez-Jurado L, González JR. scorelnvHap: inversion genotyping for genome-wide association studies. Zhu X, editor. PLOS Genet [Internet]. Public Library of Science; 2019 [cited 2019 Jul 18];15:e1008203. Available from: https://doi.org/10.1371/journal.pgen.1008203

9. González JR, Cáceres A, Esko T, Cuscó I, Puig M, Esnaola M, et al. A common 16 p11.2 inversion underlies the joint susceptibility to asthma and obesity. Am J Hum Genet [Internet]. 2014 [cited 2015 May 7];94:361-372. Available from: http://www.pubmedcentral.nih.gov/articlerender.fcgi?artid=395194 0\&tool=pmcentrez\&rendertype $=$ abstract

10. Okbay A, Baselmans BML, De Neve J-E, Turley P, Nivard MG, Fontana MA, et al. Genetic variants associated with subjective well-being, depressive symptoms, and neuroticism identified through genome-wide analyses. Nat Genet [Internet]. NIH Public Access; 2016 [cited 2017 May 4];48:624-633. Available from: http://www.ncbi.nlm.nih.gov/pubmed/27089181

11. Permuth-Wey J, Lawrenson K, Shen HC, Velkova A, Tyrer JP, Chen Z, et al. Identification and molecular characterization of a new ovarian cancer susceptibility locus at 17q21.31. Nat Commun [Internet]. Nature Publishing Group; 2013 [cited 2018 Jun 12];4:1627. Available from: http://www.nature. com/articles/ncomms2613

12. Cáceres A, González JR. Following the footprints of polymorphic inversions on SNP data: from detection to association tests. Nucleic Acids Res [Internet]. 2015 [cited 2015 Feb 17];1-11. Available from: http://www.ncbi. nlm.nih.gov/pubmed/25672393

13. Grossman RL, Heath AP, Ferretti V, Varmus HE, Lowy DR, Kibbe WA, et al. Toward a shared vision for cancer genomic data. N Engl J Med [Internet]. Massachusetts Medical Society; 2016 [cited 2018 Sep 27];375:1109-1112. Available from: https://doi.org/10.1056/NEJMp1607591

14. Li Ding's Lab. birdseed2vcf [Internet]. [cited 2019 Oct 1]. Available from: https://github.com/ding-lab/birdseed2vcf

15. Das S, Forer L, Schönherr S, Sidore C, Locke AE, Kwong A, et al. Nextgeneration genotype imputation service and methods. Nat Genet [Internet] 2016 [cited 2017 May 29];48:1284-7. Available from: http://www.ncbi.nlm. nih.gov/pubmed/27571263

16. Pedersen BS, Quinlan AR. Who's who? detecting and resolving sample anomalies in human DNA sequencing studies with peddy. Am J Hum Genet [Internet]. Elsevier; 2017 [cited 2018 Feb 2];100:406-13. Available from: http://www.ncbi.n/m.nih.gov/pubmed/28190455

17. scorelnvHap Bioconductor version [Internet]. [cited 2018 Jun 11]. Available from: https://bioconductor.org/packages/release/bioc/html/scorelnvHap.html

18. WHO. Cancer - fact sheets [Internet]. 2016 [cited 2019 Oct 1]. Available from: https://www.who.int/news-room/fact-sheets/detail/cancer

19. Ramos M, Waldron L, Schiffer L, Obenchain V MM. curatedTCGAData: curated data from The Cancer Genome Atlas (TCGA) as MultiAssayExperiment Objects. [Internet]. 2018. Available from: https://bioconductor.org/packages/release/ data/experiment/html/curatedTCGAData.html

20. Owzar K, Li Z, Cox N, Jung S-H. Power and sample size calculations for SNP association studies with censored time-to-event outcomes. Genet Epidemiol [Internet]. NIH Public Access; 2012 [cited 2019 Oct 2];36:538-48. Available from: http://www.ncbi.nlm.nih.gov/pubmed/22685040

21. Viechtbauer $\mathbf{W}$. Conducting meta-analyses in $R$ with the metafor Package. J Stat Softw [Internet]. 2010 [cited 2018 Sep 25];36:1-48. Available from: http://www.jstatsoft.org/v36/i03/

22. Colaprico A, Silva TC, Olsen C, Garofano L, Cava C, Garolini D, et al. TCGAbiolinks : an R/Bioconductor package for integrative analysis of TCGA data. Nucleic Acids Res [Internet]. Oxford University Press; 2016 [cited 2017 Jan 13];44:e71. Available from: https://doi.org/10.1093/nar/gkv1507

23. Law CW, Chen Y, Shi W, Smyth GK. voom: precision weights unlock linear model analysis tools for RNA-seq read counts. Genome Biol [Internet]. BioMed Central; 2014 [cited 2015 Jan 7];15:R29. Available from: https://doi.org/10.1186/gb-2014-15-2-r29

24. Ruiz-Arenas C, González JR. Redundancy analysis allows improved detection of methylation changes in large genomic regions. BMC Bioinformatics [Internet]. 2017 [cited 2018 Jan 25];18:553. Available from: http://www.ncbi. nlm.nih.gov/pubmed/29237399

25. Ruiz C, Hernandez-Ferrer C, González J. MEAL: perform methylation analysis. R package version 1.10.0 [Internet]. 2016. Available from: https://bioconductor. org/packages/release/bioc/html/MEAL.html
26. Benjamini $Y$, Hochberg Y. Controlling the false discovery rate: a practical and powerful approach to multiple testing. J R Stat Soc Ser B [Internet]. 1995;57:289-300 Available from: http://www.jstor.org/stable/2346101.

27. Durinck S, Moreau Y, Kasprzyk A, Davis S, De Moor B, Brazma A, et al. BioMart and Bioconductor: a powerful link between biological databases and microarray data analysis. Bioinformatics [Internet]. 2005 [cited 2018 Sep 25];21: 3439-3440. Available from: http://www.ncbi.nlm.nih.gov/pubmed/16082012

28. Durinck S, Spellman PT, Birney E, Huber W. Mapping identifiers for the integration of genomic datasets with the R/Bioconductor package biomaRt. Nat Protoc [Internet]. NIH Public Access; 2009 [cited 2018 Sep 25];4:11841191. Available from: http://www.ncbi.nlm.nih.gov/pubmed/19617889

29. Aryee MJ, Jaffe AE, Corrada-Bravo H, Ladd-Acosta C, Feinberg AP, Hansen $K D$, et al. Minfi: a flexible and comprehensive Bioconductor package for the analysis of Infinium DNA methylation microarrays. Bioinformatics [Internet]. 2014 [cited 2015 Jan 9];30:1363-1369. Available from: http://bioinformatics. oxfordjournals.org/content/30/10/1363

30. Chen Y, Lemire M, Choufani S, Butcher DT, Grafodatskaya D, Zanke BW, et al. Discovery of cross-reactive probes and polymorphic CpGs in the Illumina Infinium HumanMethylation450 microarray. Epigenetics [Internet]. 2013 [cited 2015 Sep 1];8:203-209. Available from: http://www.pubmedcentral.nih. gov/articlerender.fcgi?artid=3592906\&tool=pmcentrez\&rendertype=abstract

31. Jaffe AE, Murakami $P$, Lee $H$, Leek JT, Fallin MD, Feinberg AP, et al. Bump hunting to identify differentially methylated regions in epigenetic epidemiology studies. Int J Epidemiol [Internet]. 2012 [cited 2014 Jul 11];41: 200-209. Available from: http://ije.oxfordjournals.org.sare.upf.edu/ content/41/1/200.abstract?ijkey = 4c57d302c5abddde4a9156a729dd9f514a7223c7\&keytype2 = tf_ipsecsha

32. Peters T, Buckley M, Statham A, Pidsley R, Samaras K, Lord R, et al. De novo identification of differentially methylated regions in the human genome. Epigenetics Chromatin [Internet]. 2015 [cited 2015 Feb 10];8:6. Available from: http://www.epigeneticsandchromatin.com/content/8/1/6

33. Tingley $D$, Yamamoto $T$, Hirose $K$, Keele $L$, Imai K. Mediation : $R$ package for causal mediation analysis. J Stat Softw [Internet]. 2014 [cited 2018 Jul 9];59: 1-38. Available from: http://www.jstatsoft.org/v59/i05/

34. Itsara A, Vissers LELM, Steinberg KM, Meyer KJ, Zody MC, Koolen DA, et al. Resolving the breakpoints of the 17q21.31 microdeletion syndrome with next-generation sequencing. Am J Hum Genet [Internet]. Elsevier; 2012 [cited 2018 Nov 5];90:599-613. Available from: http://www.ncbi.nlm.nih.gov/ pubmed/22482802

35. Zhang N, Huo Q, Wang X, Chen X, Long L, Guan X, et al. A genetic variant in p63 ( $r$ 17506395) is associated with breast cancer susceptibility and prognosis. Gene [Internet]. Elsevier; 2014 [cited 2018 Sep 26];535:170-176. Available from: https://www.sciencedirect.com/science/article/pii/S0378111 913015643?via\%3Dihub

36. Rafiq S, Tapper W, Collins A, Khan S, Politopoulos I, Gerty S, et al. Identification of inherited genetic variations influencing prognosis in earlyonset breast cancer. Cancer Res [Internet]. American Association for Cancer Research; 2013 [cited 2018 Jun 18];73:1883-1891. Available from: http://www.ncbi.nlm.nih.gov/pubmed/23319801

37. Rafiq S, Khan S, Tapper W, Collins A, Upstill-Goddard R, Gerty S, et al. A genome wide meta-analysis study for identification of common variation associated with breast cancer prognosis. Miao X, editor. PLoS One [Internet]. 2014 [cited 2018 Jun 1];9:e101488. Available from: https://doi.org/10.1371/ journal.pone.0101488

38. Wang $X$, Lin $Y$, Lan F, Yu Y, Ouyang $X$, Wang $X$, et al. A GG allele of $3^{\prime}$-side AKT1 SNP is associated with decreased AKT1 activation and better prognosis of gastric cancer. J Cancer Res Clin Oncol [Internet]. 2014 [cited 2018 Sep 26];140:1399-1411. Available from: http://www.ncbi.nlm.nih.gov/ pubmed/24737346

39. Tahara T, Okubo M, Shibata T, Kawamura T, Sumi K, Ishizuka T, et al. Association between common genetic variants in pre-microRNAs and prognosis of advanced gastric cancer treated with chemotherapy. Anticancer Res [Internet]. 2014 [cited 2018 Sep 26];34:5199-5204. Available from: http://www.ncbi.nlm.nih.gov/pubmed/25202115

40. Kim JG, Chae YS, Lee SJ, Kang BW, Park JY, Lee E-J, et al. Genetic variation in microRNA-binding site and prognosis of patients with colorectal cancer. J Cancer Res Clin Oncol [Internet]. 2015 [cited 2018 Sep 26];141:35-41. Available from: http://www.ncbi.nlm.nih.gov/ pubmed/25079514

41. Lee SJ, Kang BW, Chae YS, Kim HJ, Park SY, Park JS, et al. Genetic variations in STK11, PRKAA1, and TSC1 associated with prognosis for patients with 
colorectal cancer. Ann Surg Oncol [Internet]. 2014 [cited 2018 Sep 26];21: 634-639. Available from: http://www.ncbi.nlm.nih.gov/pubmed/24770722

42. Haja Mohideen AMS, Hyde A, Squires J, Wang J, Dicks E, Younghusband B, et al. Examining the polymorphisms in the hypoxia pathway genes in relation to outcome in colorectal cancer. PLoS One [Internet]. Public Library of Science; 2014 [cited 2018 Sep 26];::e113513. Available from: http://www. ncbi.nlm.nih.gov/pubmed/25405996

43. Song N, Kim K, Shin A, Park JW, Chang HJ, Shi J, et al. Colorectal cancer susceptibility loci and influence on survival. Genes, Chromosom Cancer [Internet]. John Wiley \& Sons, Ltd; 2018 [cited 2019 Sep 9];57:630-637. Available from: https://doi.org/10.1002/gcc.22674

44. He Y, Theodoratou E, Li X, Din FVN, Vaughan-Shaw P, Svinti V, et al. Effects of common genetic variants associated with colorectal cancer risk on survival outcomes after diagnosis: a large population-based cohort study. Int J Cancer [Internet]. John Wiley \& Sons, Ltd; 2019 [cited 2019 Sep 9];145: 2427-2432. Available from: https://doi.org/10.1002/ijc.32550

45. Namjou B, Ni Y, Harley ITW, Chepelev I, Cobb B, Kottyan LC, et al. The effect of inversion at $8 p 23$ on BLK association with lupus in Caucasian population. PLoS One [Internet]. 2014 [cited 2015 May 18];9:e115614. Available from: http://www.pubmedcentral.nih.gov/articlerender.fcgi?artid $=4278715 \&$ tool $=$ pmcentrez\&rendertype $=$ abstract

46. Demirci FY, Wang X, Morris DL, Feingold E, Bernatsky S, Pineau C, et al. Multiple signals at the extended 8p23 locus are associated with susceptibility to systemic lupus erythematosus. J Med Genet [Internet]. 2017 [cited 2018 Nov 21];54:381-389. Available from: http://www.ncbi.nlm.nih. gov/pubmed/28289186

47. Gutiérrez Arumi A. Ancestral genomic submicroscopic inversions of human genome and their relation with multifactorial human diseases. Univ Pompeu Fabra [Internet]. Universitat Pompeu Fabra; 2015 [cited 2018 Jan 25]; Available from: https://repositori.upf.edu/handle/10230/33134

48. Vandrovcova J, Pittman AM, Malzer E, Abou-Sleiman PM, Lees AJ, Wood NW, et al. Association of MAPT haplotype-tagging SNPs with sporadic Parkinson's disease. Neurobiol Aging [lnternet]. 2009 [cited 2018 Nov 28];30: 1477-1482. Available from: http://www.ncbi.nlm.nih.gov/pubmed/18162161

49. Tobin JE, Latourelle JC, Lew MF, Klein C, Suchowersky O, Shill HA, et al. Haplotypes and gene expression implicate the MAPT region for Parkinson disease: the GenePD Study. Neurology [Internet]. NIH Public Access; 2008 [cited 2018 Nov 29];71:28-34. Available from: http://www.ncbi.nIm.nih.gov/ pubmed/18509094

50. Setó-Salvia N, Clarimón J, Pagonabarraga J, Pascual-Sedano B, Campolongo A, Combarros O, et al. Dementia risk in Parkinson disease. Arch Neurol [Internet]. 2011 [cited 2018 Nov 29];68:359-364. Available from: http://www. ncbi.nlm.nih.gov/pubmed/21403021

51. Goris A, Williams-Gray CH, Clark GR, Foltynie T, Lewis SJG, Brown J, et al. Tau and a-synuclein in susceptibility to, and dementia in, Parkinson's disease. Ann Neurol [Internet]. 2007 [cited 2018 Nov 29];62:145-153. Available from: http://www.ncbi.nlm.nih.gov/pubmed/17683088

52. Webb A, Miller B, Bonasera S, Boxer A, Karydas A, Wilhelmsen KC. Role of the tau gene region chromosome inversion in progressive supranuclear palsy, corticobasal degeneration, and related disorders. Arch Neurol [Internet]. NIH Public Access; 2008 [cited 2017 Mar 16];65:1473-1478. Available from: http://www.ncbi.nlm.nih.gov/pubmed/19001166

53. Li Y, Chen JA, Sears RL, Gao F, Klein ED, Karydas A, et al. An epigenetic signature in peripheral blood associated with the haplotype on 17q21.31, a risk factor for neurodegenerative tauopathy. PLoS Genet [Internet]. 2014 [cited 2015 Apr 27];10:e1004211. Available from: http://www.pubmedcentral. nih.gov/articlerender.fcgi?artid $=3945475 \&$ tool $=$ pmcentrez\&rendertype $=$ abstract

54. Myers AJ, Kaleem M, Marlowe L, Pittman AM, Lees AJ, Fung HC, et al. The H1c haplotype at the MAPT locus is associated with Alzheimer's disease. Hum Mol Genet [lnternet]. Oxford University Press; 2005 [cited 2018 Nov 29]; 14:23992404. Available from: http://academic.oup.com/hmg/article/14/16/2399/6756 73/The-H1 c-haplotype-at-the-MAPT-locus-is-associated

55. Tantisira KG, Lazarus R, Litonjua AA, Klanderman B, Weiss ST. Chromosome 17: association of a large inversion polymorphism with corticosteroid response in asthma. Pharmacogenet Genomics [Internet]. NIH Public Access; 2008 [cited 2018 Jan 25];18:733-737. Available from: http://www.ncbi.nlm. nih.gov/pubmed/18622266

56. Nomura T, Suzuki S, Miyauchi T, Takeda M, Shinkuma S, Fujita Y, et al. Chromosomal inversions as a hidden disease-modifying factor for somatic recombination phenotypes. JCl insight [Internet]. American Society for
Clinical Investigation; 2018 [cited 2018 Nov 8];3. Available from: http://www. ncbi.nlm.nih.gov/pubmed/29563344

57. de Jong $\mathrm{S}$, Chepelev I, Janson E, Strengman E, van den Berg LH, Veldink JH, et al. Common inversion polymorphism at 17q21.31 affects expression of multiple genes in tissue-specific manner. BMC Genomics [Internet]. 2012 [cited 2015 Apr 27];13:458. Available from: http://www.pubmedcentral.nih. gov/articlerender.fcgi?artid=3582489\&tool=pmcentrez\&rendertype $=$ abstract

58. Allen M, Kachadoorian M, Quicksall Z, Zou F, Chai H, Younkin C, et al. Association of MAPT haplotypes with Alzheimer's disease risk and MAPT brain gene expression levels. Alzheimers Res Ther [Internet]. BioMed Central; 2014 [cited 2018 Jun 12];6:39. Available from: https://doi.org/10.1186/ alzrt268

59. Myers AJ, Gibbs JR, Webster JA, Rohrer K, Zhao A, Marlowe L, et al. A survey of genetic human cortical gene expression. Nat Genet [Internet]. Nature Publishing Group; 2007 [cited 2018 Jun 12];39:1494-1499. Available from: http://www.nature.com/articles/ng.2007.16

60. International Parkinson Disease Genomics Consortium, Nalls MA, Plagnol V, Hernandez DG, Sharma M, Sheerin U-M, et al. Imputation of sequence variants for identification of genetic risks for Parkinson's disease: a metaanalysis of genome-wide association studies. Lancet (London, England) [Internet]. Elsevier; 2011 [cited 2018 Jun 12];377:641-9. Available from: http://www.ncbi.nlm.nih.gov/pubmed/21292315

61. Chowdhury R, Bois PRJ, Feingold E, Sherman SL, Cheung VG. Genetic analysis of variation in human meiotic recombination. Copenhaver GP, editor. PLoS Genet [Internet]. Public Library of Science; 2009 [cited 2018 Apr 12];5:e1000648. Available from: https://doi.org/10.1371/journal.pgen.1000648

62. Dallol A, Al-Maghrabi J, Buhmeida A, Gari MA, Chaudhary AG, Schulten H-J, et al. Methylation of the polycomb group target genes is a possible biomarker for favorable prognosis in colorectal cancer. Cancer Epidemiol Biomarkers Prev [Internet]. American Association for Cancer Research; 2012 [cited 2018 Sep 26];21:2069-75. Available from: http://www.ncbi.nlm.nih. gov/pubmed/23010642

63. Park SJ, Kim S, Hong YS, Lee J-L, Kim J-E, Kim K, et al. TFAP2E methylation status and prognosis of patients with radically resected colorectal cancer. Oncology [Internet]. 2015 [cited 2018 Sep 26];88:122-32. Available from: http://www.ncbi.nlm.nih.gov/pubmed/25341849

\section{Publisher's Note}

Springer Nature remains neutral with regard to jurisdictional claims in published maps and institutional affiliations.

\section{Ready to submit your research? Choose BMC and benefit from:}

- fast, convenient online submission

- thorough peer review by experienced researchers in your field

- rapid publication on acceptance

- support for research data, including large and complex data types

- gold Open Access which fosters wider collaboration and increased citations

- maximum visibility for your research: over $100 \mathrm{M}$ website views per year

At BMC, research is always in progress.

Learn more biomedcentral.com/submissions 